\title{
Simulation and Modal Analysis of Marine Diesel Engine Based on Finite Element Model and Vibration Sensor Data
}

\author{
Jianbin Liao, ${ }^{1,2,3}$ Hongliang Yu, ${ }^{1,3^{*}}$ Jin Yan, ${ }^{1,3}$ and Shih-Hsien Hsu ${ }^{4 * *}$ \\ ${ }^{1}$ College of Marine Engineering, Jimei University, 185 Yinjiang Road, Jimei District, Xiamen 361021, China \\ ${ }^{2}$ School of Marine Engineering, Dalian Maritime University, Dalian 116026, China \\ ${ }^{3}$ Fujian Key Laboratory of Marine Engineering, Xiamen 361021, China \\ ${ }^{4}$ Department of Electrical Engineering, Feng Chia University, Taichung 40724, Taiwan
}

(Received October 21, 2020; accepted April 16, 2021)

Keywords: marine diesel engine, modal analysis, finite element method, modal analysis, vibration sensor

The vibration characteristics of a marine diesel engine are important in optimizing its design for reducing the vibration and diagnosing the faults caused by it. In this study, we propose an appropriate simulation model by using the vibration data from vibration sensors and a 4190 ZLC marine diesel engine. The finite element model (FEM) was used for calculations that were verified by the modal test. The results showed that the fourth to sixth orders of the vibration frequencies simulated by the FEM were consistent with the measured ones within a difference of $5 \%$. The results verified that the simulation model provides a theoretical basis for improving the diesel engine structure and optimizing the design to reduce its vibration, which will contribute to preventing damage from resonance and enhancing reliability.

\section{Introduction}

Applying turbo technology to modern marine diesel engines improves their performance but causes problems from the increased weight and vibration of the engines. ${ }^{(1)}$ Severe vibration damages equipment, resulting in economic loss, and threatens the safe operation of ships. To ensure reliability and prevent possible accidents, the static dynamics and vibration characteristics of engines need to be understood. Related research is nowadays performed by using computeraided engineering, reducing the cost and time. ${ }^{(2)}$ The finite element method (FEM) also plays an important role in research as it allows the optimal design of the complex structure of the marine diesel engine with turbo technology. ${ }^{(3)}$

The FEM is applied to solve engineering problems as it enables efficient calculations. The basic idea is to discretize the solution domain of a structure or continuum into various nodes of elements and to connect the elements to form an assembly through the nodes on the boundary. The approximate function of each element represents the unknown field variables to be solved in slices of the whole domain. The values of the function and its derivatives on each node of the elements and the interpolation function corresponding to this value are obtained in the FEM. As the values of the functions on the nodes of adjacent elements are assumed to be equal, they are *Corresponding author: e-mail: yu1202@hotmail.com **Corresponding author: e-mail: shihhhsu@fcu.edu.tw https://doi.org/10.18494/SAM.20213180 
considered as the unknowns in the numerical solution to be calculated in a model by using the FEM. ${ }^{(4-6)}$ In general, an FEM model requires a lot of information about nodes, elements, and boundary conditions. The computational speed and accuracy are determined by the quality and quantity of the model mesh and how accurately the boundary conditions are defined. ${ }^{(7,8)}$ The model of a diesel engine body is meshed by grids that first need to be manually adjusted to obtain the appropriate model. An appropriate FEM model can minimize the difference between the calculation results and the measured data.

The FEM is frequently used for the modal analysis of various structures requiring numerical approximations. Modal analysis describes the characteristics of the inherent vibration of a structure and provides the basis of dynamic analysis. It allows the natural frequency, damping factor, mass, and shape of modes to be obtained. As modal analysis is linear, it ignores nonlinear options. Modal analysis helps understand the dynamic characteristics of structures in a certain frequency range and predict vibrations under various forces. It is also used to understand the relationship between the eigenvalues and eigenvectors for solving mathematical problems of structural vibration. ${ }^{(9,10)}$

By using the FEM, our aim is to establish a 3D model of a 4190 ZLC marine diesel engine that has four cylinders and a nominal power of $220 \mathrm{~kW}$. By using the model, a modal analysis of the cylinder block structure was carried out, then the performance of the cylinder block was simulated. For the simulation, the data from vibration sensors installed on the engine were analyzed. Vibration sensors such as an accelerometer, strain gauge, and eddy-current meter sense the mechanical movement caused by radial or axial vibration and measure the intensity of the vibration by using frequency response functions. The simulation framework allows rapid analysis for iterative design, contributing to the development of structures with reduced vibration. The simulation results provide basic information for improving the dynamic characteristic analysis of marine diesel engines.

\section{Methods}

\subsection{Three-dimensional model}

The 4190 ZLC marine diesel engine is shown in Fig. 1 and its performance parameters are presented in Table 1. Its cylinder block has a complex structure, which was modeled according to

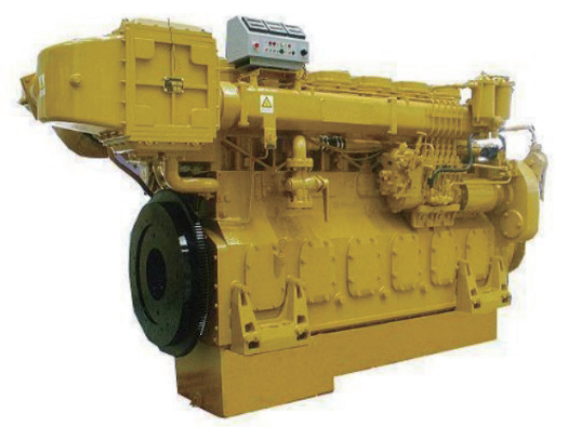

Fig. 1. (Color online) Overall structure of 4190 ZLC marine diesel engine. 
the real dimensions by using ProE 3D modeling software. The model needed to be simplified to subsequently build a FEM model of the engine. ${ }^{(11-13)}$ Some of the small parts and components with little influence on the overall structure were not included, and details such as rounded corners and tiny oil holes of $5 \mathrm{~mm}$ diameter were simplified. The whole structure and the piston connecting the rod assembly of the 4190 ZLC engine are shown in Figs. 2 and 3, respectively. The FEM models of the crankshaft connecting the rod and the engine block are shown in Figs. 4 and 5, respectively. The crankshaft, the connecting rod, and the piston pin are simplified into beam elements and rigidly connected with the bearing block by dividing the grid by degrees.

Table 1

Basic parameters of 4190 ZLC engine.

\begin{tabular}{lclc}
\hline Item & Parameter & Item & Parameter \\
\cline { 2 - 4 } Number of cylinders & 4 & Calibration of torque & $2100 \mathrm{Nm}$ \\
Cylinder diameter $\times$ stroke & $190 \mathrm{~mm} \times 210 \mathrm{~mm}$ & Maximum burst pressure & $12 \mathrm{MPa}$ \\
Nominal power & $220 \mathrm{~kW}$ & Calibration speed & $1000 \mathrm{RPM}$ \\
\hline
\end{tabular}

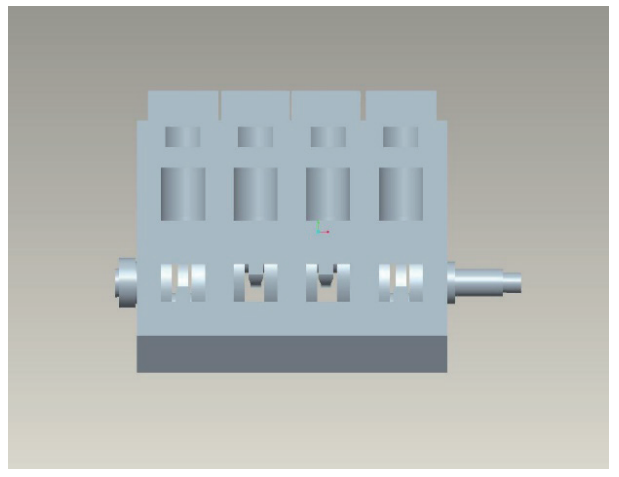

Fig. 2. (Color online) 3D model of engine block of 4190 ZLC marine diesel engine.

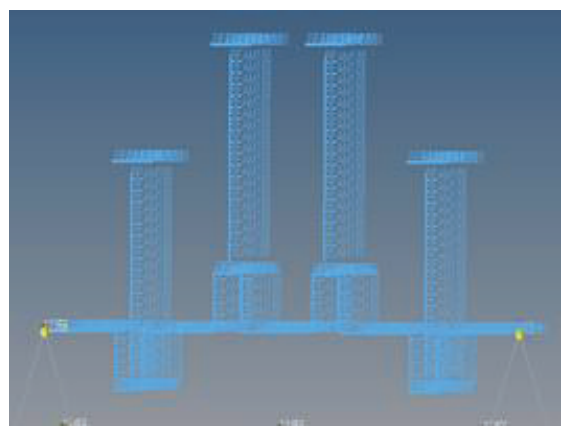

Fig. 4. (Color online) FEM model of the crankshaft connecting the rod assembly.

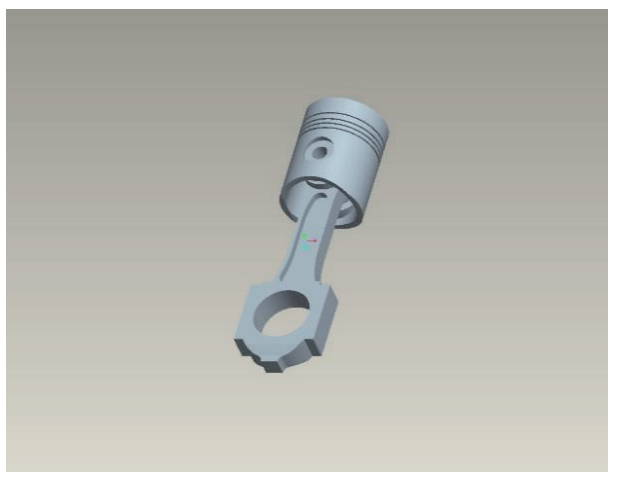

Fig. 3. (Color online) 3D model of the piston connecting the rod assembly.

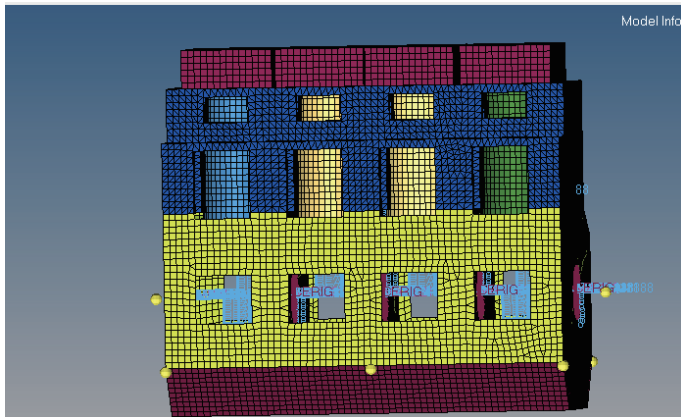

Fig. 5. (Color online) FEM model of the 4190 ZLC engine block. 


\subsection{Measurement of vibration}

By using a signal acquisition method, the actual vibration response was observed for the modal analysis. $\mathrm{LMS}^{\mathrm{TM}}$ testing (Siemens) was used as the data acquisition instrument. A triaxial acceleration sensor (PCB-ICP356A16) with a sensitivity of $100 \mathrm{mV} / \mathrm{g}$ and a frequency range of 0.5 to $5 \mathrm{kHz}$ was used to measure and record the vibration response signal of the engine. Figures 6 and 7 show a photograph and schematic diagram of the test system used for the modal analysis, respectively.

\subsection{Modal analysis of $4190 \mathrm{ZLC}$}

Without considering damping, the differential equation of the vibration of a structure is defined as

$$
[M]\{\ddot{x}\}+[K]\{x\}=0,
$$

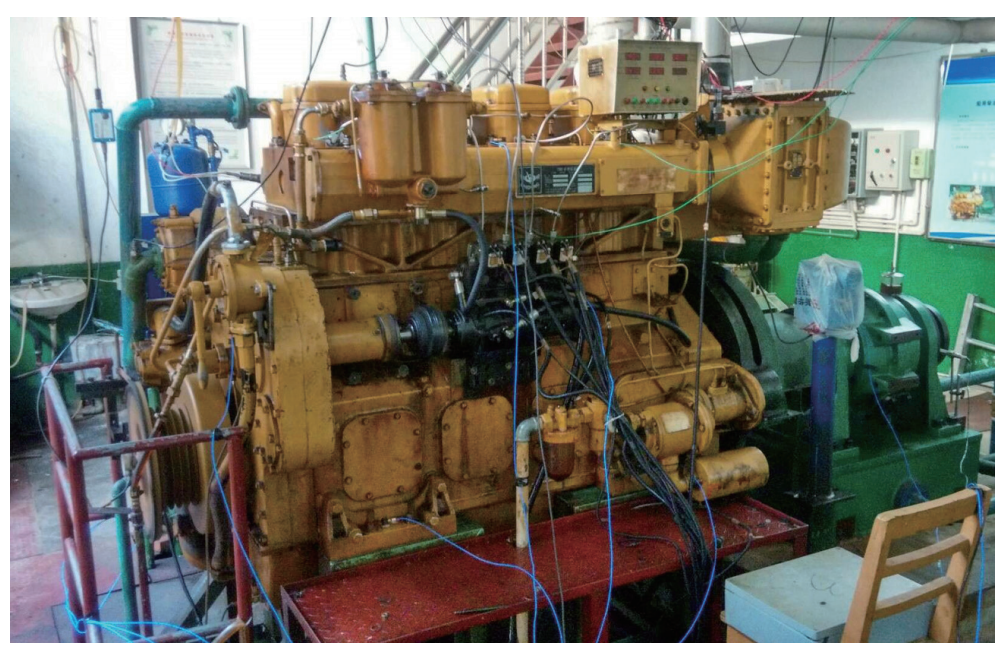

Fig. 6. (Color online) Photograph of the 4190 ZLC engine with measuring devices.

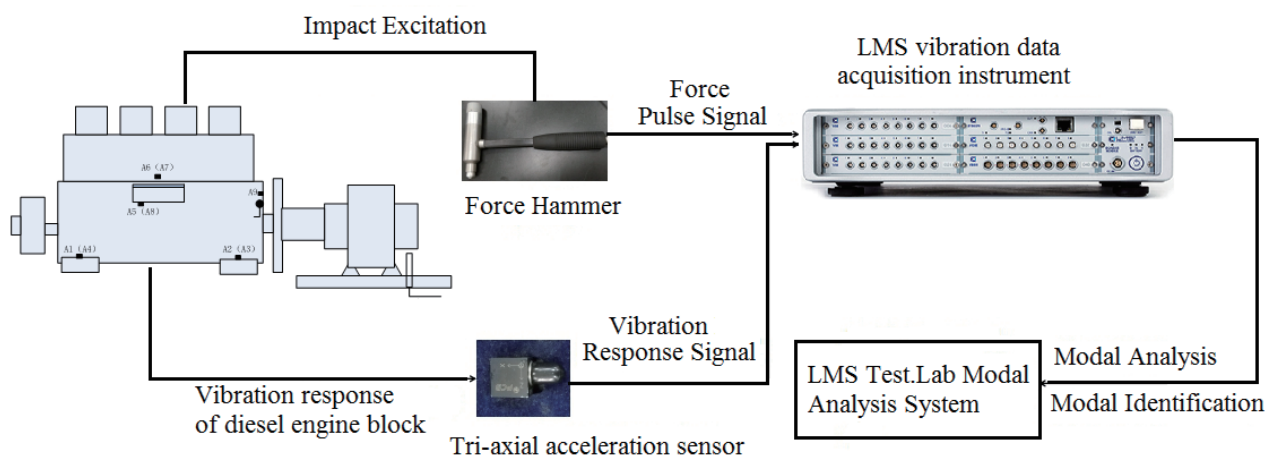

Fig. 7. (Color online) Schematic diagram of the modal test system. 
where $[M]$ is the mass matrix of the system, $[K]$ is the stiffness matrix of the system, and $\{x\}$ and $\{\ddot{x}\}$ are the displacement and acceleration vectors of the vibration of the diesel engine system, respectively.

Solving Eq. (1) gives the natural frequency and the main mode of the vibration of the diesel engine. The solution of Eq. (1) is

$$
\{x\}=\{X\} e^{j \omega t},
$$

where $\{X\}$ is the amplitude vector of the displacement. Substituting Eq. (2) and its second derivative with respect to time into Eq. (1) and eliminating the factor $e^{j \omega t}$, we obtain

$$
\left([K]-\omega^{2}[M]\right)\{X\}=0 .
$$

Then, Eq. (3) is expressed as

$$
\operatorname{det}\left|[K]-\omega^{2}[M]\right|=0 \text {. }
$$

The above equations give the corresponding displacement amplitude vector $\{X\}$, the natural mode of vibration $\left\{\phi_{i}\right\}$, and the natural frequency of the system $\omega_{i}(i=1,2, \ldots, n)$ by substituting $\omega_{i}$ into Eq. (3).

\subsection{Material properties and boundary conditions}

To investigate the influence of the bottom constraints, the 4190 ZLC marine diesel engine was fixed on an angle bracket that was anchored by bolts on the ground. The bottom constraints are shown in Fig. 8. The FEM model of the region connecting the diesel engine body and oil sump is shown in Fig. 9.

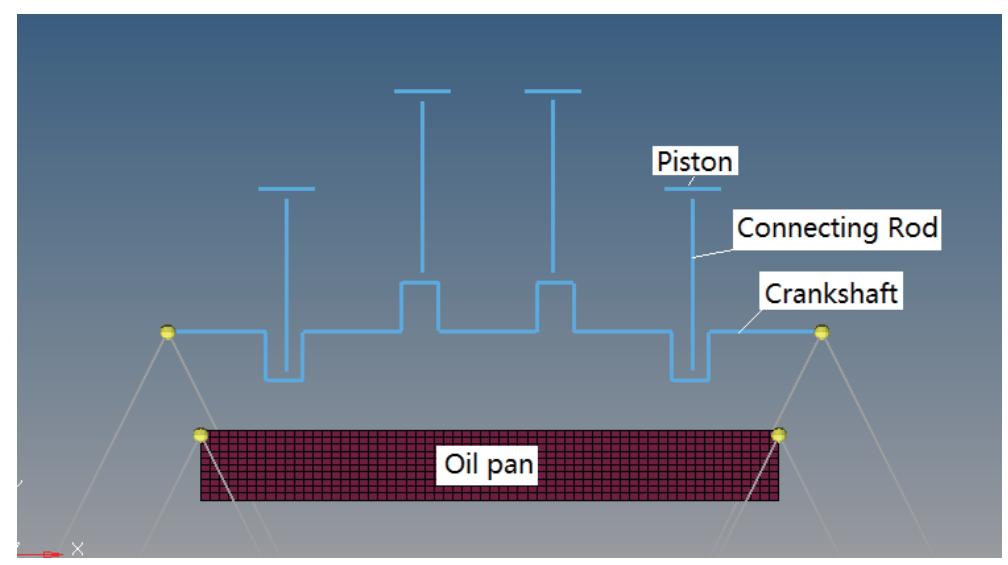

Fig. 8. (Color online) Bottom constraints of the 4190 ZLC engine. 


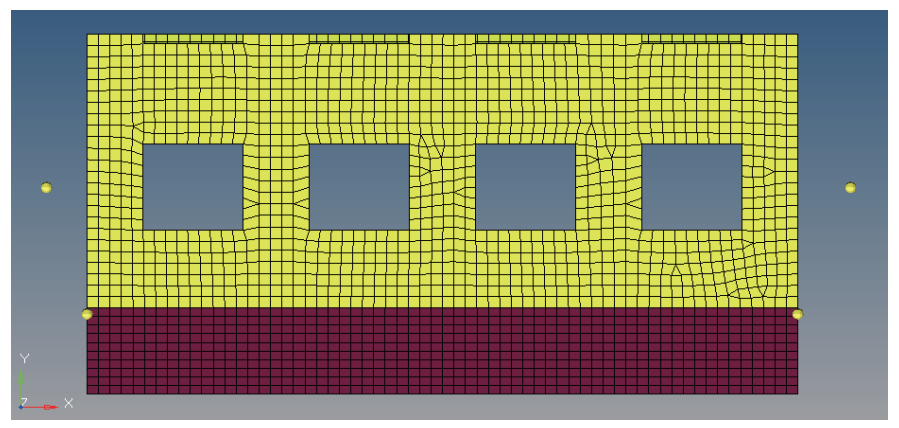

Fig. 9. (Color online) FEM model of the region connecting the oil sump and the body.

The oil pan and engine block were integrated by using a joint coupling model.(14) Owing to the surface contact between the cylinder sleeve and the body, the connection mode of the contacting pair was adopted. It was assumed that there was a lubrication film layer between the piston ring and the cylinder liner and on the spring connection. The two ends of the crankshaft were connected with a hydraulic dynamometer and flywheel, which rotated without full restraint at a fixed location. A FEM model based on the described structure was established by considering the material properties of relevant components (Table 2).

\section{Results and Discussion}

\subsection{Modal analysis of structure of 4190 ZLC engine}

SOLID185 elements were used for the 3D modeling of the engine body and cylinder sleeve piston, and BEAM188 elements were used for the crankshaft connecting the rod. SHELL181 elements were adopted to analyze the shell unit. The SOLID185, BEAM188, and SHELL181 elements used in the simulation of the 3D structural model are appropriate for modeling a 3D solid structure, a slender to moderately thick beam structure, and a thin to moderately thick shell structure, respectively. By using ANSYS modal analysis and calculation, the overall modal simulation was carried out to obtain the inherent frequencies of the $4190 \mathrm{ZMC}$ engine as shown in Table 3.

Table 2

Physical properties of materials in each part of 4190 ZLC engine.

\begin{tabular}{lccc}
\hline Part name & $\begin{array}{c}\text { Modulus of } \\
\text { elasticity }(\mathrm{GPa})\end{array}$ & Poisson's ratio & $\begin{array}{c}\text { Density } \\
\left(\mathrm{kg} / \mathrm{m}^{3}\right)\end{array}$ \\
\hline Cylinder liner & 120 & 0.3 & 7300 \\
Crankshaft & 150 & 0.25 & 7300 \\
Cylinder head & 170 & 0.275 & 7100 \\
Body & 170 & 0.275 & 7100 \\
Oil pan & 210 & 0.27 & 7900 \\
Bearing & 200 & 0.275 & 7100 \\
Piston & 72 & 0.3 & 2700 \\
\hline
\end{tabular}


Table 3

Results of the modal analysis of the 4190 ZLC engine with FEM.

\begin{tabular}{cccccc}
\hline $\begin{array}{c}\text { First-order } \\
\text { frequency }(\mathrm{Hz})\end{array}$ & $\begin{array}{c}\text { Second-order } \\
\text { frequency }(\mathrm{Hz})\end{array}$ & $\begin{array}{c}\text { Third-order } \\
\text { frequency }(\mathrm{Hz})\end{array}$ & $\begin{array}{c}\text { Fourth-order } \\
\text { frequency }(\mathrm{Hz})\end{array}$ & $\begin{array}{c}\text { Fifth-order } \\
\text { frequency }(\mathrm{Hz})\end{array}$ & $\begin{array}{c}\text { Sixth-order } \\
\text { frequency }(\mathrm{Hz})\end{array}$ \\
\hline 5.1146 & 11.228 & 15.929 & 19.883 & 29.261 & 49.083 \\
\hline
\end{tabular}

\subsection{Structural modal analysis}

Modal analysis with a FEM model solves the dynamics problems of a complex structure ${ }^{(15)}$ and contributes to studying the dynamic characteristics of structures. Comparison of the results of the modal analysis and the model verifies the rationality of an analysis model as the model provides the necessary correction for the modal analysis to improve the result.

In a vibration system, the external force causes vibrations. Thus, by considering force and vibration as the input and output, respectively, the vibration characteristics are analyzed under the effect of a dynamic load, node displacement, and the variation of velocity and acceleration. ${ }^{(16,17)}$ Equation (5), a second-order differential equation, ${ }^{(18,19)}$ is used to obtain the solution in the analysis.

$$
[M]\{\ddot{q}\}+[C]\{\dot{q}\}+[K]\{q\}=[F]
$$

Using the matrices $[K],[M]$, and $[C]$, the orthogonality of the modal matrix $[\Phi]$ is defined as follows:

$$
\begin{gathered}
{[\Phi]^{T}[K][\Phi]=[\bar{K}]} \\
{[\Phi]^{T}[M][\Phi]=[\bar{M}]} \\
{[\Phi]^{T}[C][\Phi]=[\bar{C}]}
\end{gathered}
$$

where $[\Phi]$ is the matrix of the modes of each order, $[\Phi]=\left[\Phi_{1}, \Phi_{2}, \ldots, \Phi_{n}\right]$.

When the modal transformation is defined as

$$
\{q\}=[\Phi]\{x\},
$$

the system of the differential equations is reduced to the following uncoupled second-order differential equation expressed in modal coordinates $(x)$ :

$$
[\bar{M}]\{\ddot{x}\}+[\bar{C}]\{\dot{x}\}+[\bar{K}]\{x\}=\{\bar{F}(t)\},
$$

where $\{\bar{F}(t)\}=[\Phi]^{T}\{F(t)\}$. 
As $[\bar{M}],[\bar{K}]$, and $[\bar{C}]$ are diagonal matrices, these equations include $n$ independent linear differential equations, $m_{i} \ddot{x}_{i}+c_{i} \dot{x}_{i}+k x_{i}=F_{i}(t)(i=1,2, \ldots, n)$. The solution of each of these $n$ equations gives $n$ values of $x_{i}$. When they are substituted back into Eq. (7), the dynamic response $\{q\}$ is obtained.

According to the theory of structural vibration, the dynamic response of a structure under a dynamic load is expressed as the linear superposition of its main modes as follows:

$$
\{q\}=x_{1}\left\{\Phi_{1}\right\}+x_{2}\left\{\Phi_{2}\right\}+\ldots+x_{n}\left\{\Phi_{n}\right\}=[\Phi]\{x\}
$$

where $x_{1}, x_{2}, \ldots, x_{n}$ are the combination coefficients, also known as the modal coordinate $\{x\}=\left\{x_{1}, x_{2}, \ldots, x_{n}\right\}$.

As a structural dynamic response is mainly from low-order modes, the low-frequency modes are considered in the computation and are used as basis eigenvector derivatives for the simulation in a dynamic analysis. The tri-axial sensor collected the vibration signals, and then the LMS converted them to digital signals that were transferred to the system for modal analysis. The collected data were processed to obtain the low-order modal parameters and the corresponding vibration modes. The test results are presented in Table 4. The translational and rotational motions of the vibrations at each frequency are shown in Figs. 10-14. Once a set of mode orders has been calculated for a system, the response at any frequency can be obtained by superimposition. It is not necessary to use the result from each mode order, and good approximate solutions are obtained with only a few mode orders. In this study, we chose the first six orders.

Table 4

Result of the modal analysis of the 4190 ZLC engine.

\begin{tabular}{cccccc}
\hline $\begin{array}{c}\text { First-order } \\
\text { frequency }(\mathrm{Hz})\end{array}$ & $\begin{array}{c}\text { Second-order } \\
\text { frequency }(\mathrm{Hz})\end{array}$ & $\begin{array}{c}\text { Third-order } \\
\text { frequency }(\mathrm{Hz})\end{array}$ & $\begin{array}{c}\text { Fourth-order } \\
\text { frequency }(\mathrm{Hz})\end{array}$ & $\begin{array}{c}\text { Fifth-order } \\
\text { frequency }(\mathrm{Hz})\end{array}$ & $\begin{array}{c}\text { Sixth-order } \\
\text { frequency }(\mathrm{Hz})\end{array}$ \\
\hline 5.968 & 9.620 & 14.757 & 19.949 & 29.686 & 49.815 \\
\hline
\end{tabular}

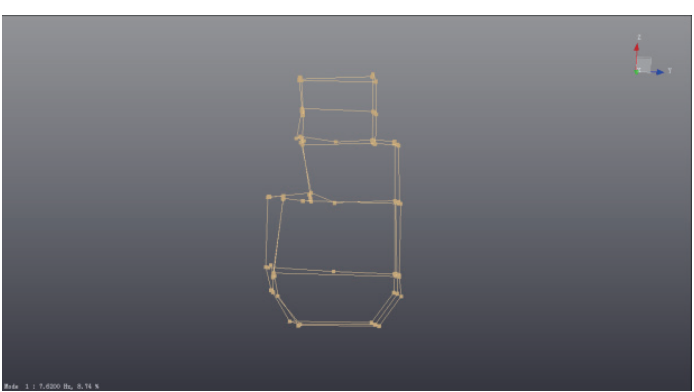

Fig. 10. (Color online) Shape of the translational mode in the $y$-direction at $9.620 \mathrm{~Hz}$.

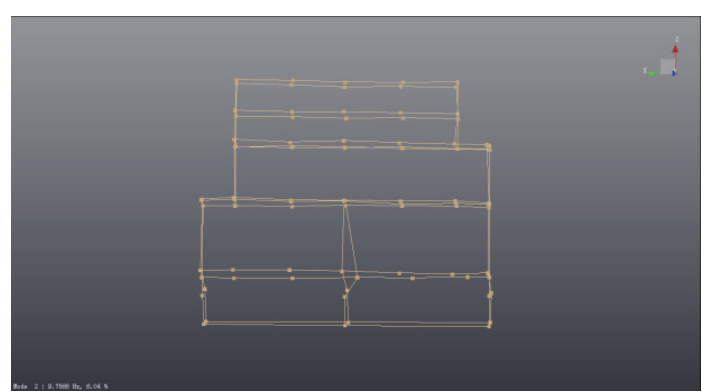

Fig. 11. (Color online) Shape of the translational mode in the $x$-direction at $14.75 \mathrm{~Hz}$. 


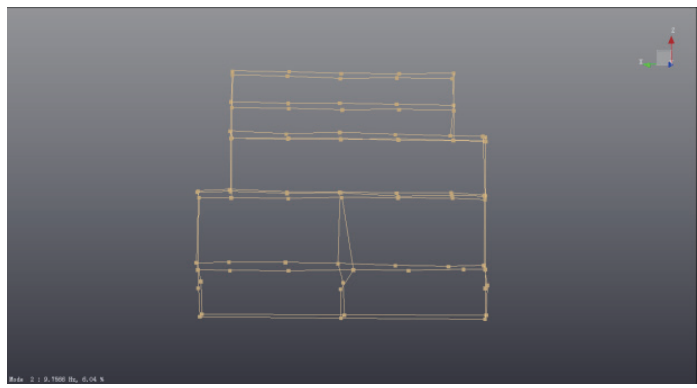

Fig. 12. (Color online) Shape of the rotational mode in the $z$-direction at $19.949 \mathrm{~Hz}$.

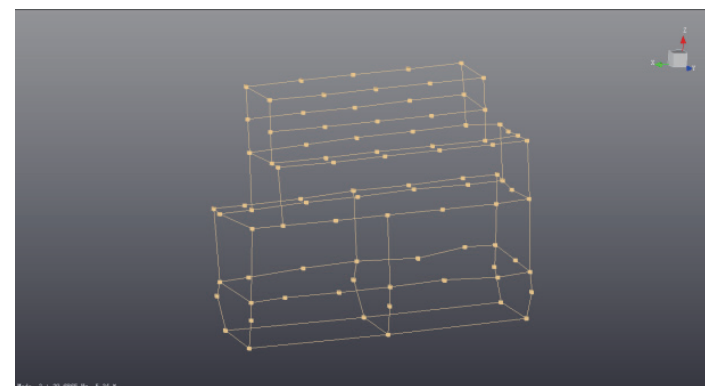

Fig. 13. (Color online) Shape of the rotational mode in the $y$-direction at $29.686 \mathrm{~Hz}$.

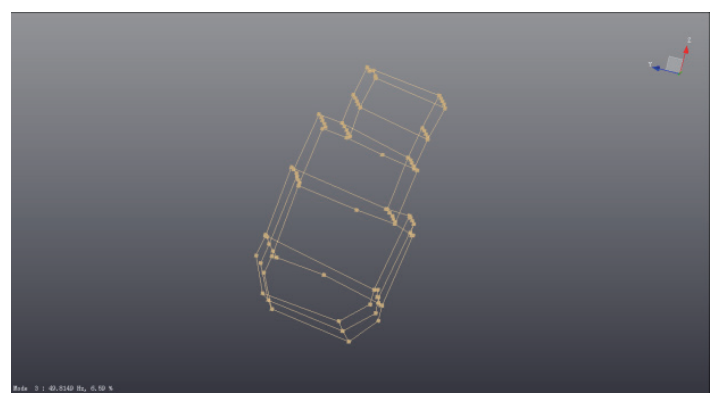

Fig. 14. (Color online) Shape of the rotational mode in the $x$-direction at $49.815 \mathrm{~Hz}$.

\subsection{Comparison of modal analysis and simulation}

To obtain reliable results, the stiffness of the body of the 4190 ZLC engine was considered when simulating the FEM model. The results are shown in Table 5. The results of the simulation of the FEM model and the modal analysis of the measured data showed that the difference in the natural frequency for the same order was less than $1.5 \%$. That is, the established model successfully simulated the actual structure of the 4190 ZLC engine and was appropriate for dynamic analysis.

Figures 15-17 present the results of the calculation and the comparison of different vibration modes and frequencies in the fourth to sixth orders of the model. The comparison of the experimental data and the simulation results reveals that the overall structure and materials of the 4190 ZLC engine were simulated successfully as the difference in the frequencies at the fourth, fifth, and sixth orders was only $1.5 \%$. Simplifying the structures of small parts and components and ignoring the effects of tiny holes with little impact on the overall vibration response contributed to the acceptable simulation result with the FEM model. However, there is still a small difference between the experimental data and the simulation results as the model considered the ideal elastic modulus, Poisson's ratio, density, and material properties. The structural relationship between the cylinder head, body, oil pan, bolt connections, and other parts in the 4190 ZLC engine also has an impact on the vibration response, which affects the modal analysis results. The results are expected to significantly improve the standard of diesel engine design and the design process. The model will reduce the time required from creating a 
Table 5

Comparison of errors of modal data.

\begin{tabular}{lccc}
\hline Data and error & Fourth-order frequency & Fifth-order frequency & Sixth-order frequency \\
\hline Experimental data (Hz) & 19.949 & 29.686 & 49.815 \\
Simulation data (Hz) & 19.883 & 29.261 & 49.083 \\
Difference (\%) & 0.33 & 1.4 & 1.5 \\
\hline
\end{tabular}

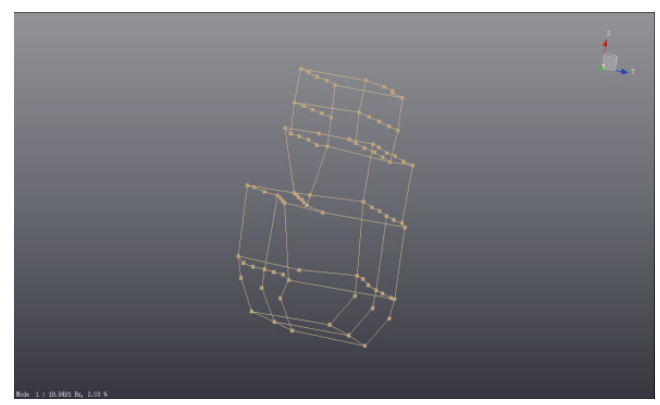

(a)

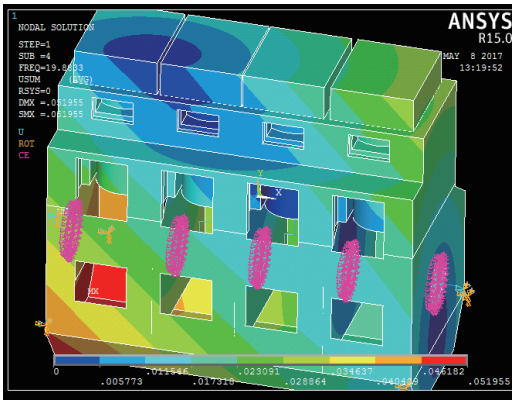

(b)

Fig. 15. (Color online) Vibration mode and frequency in the fourth-order system of the 4190 ZLC engine. (a) Natural frequency of $19.949 \mathrm{~Hz}$. (b) Simulation result of $19.883 \mathrm{~Hz}$.

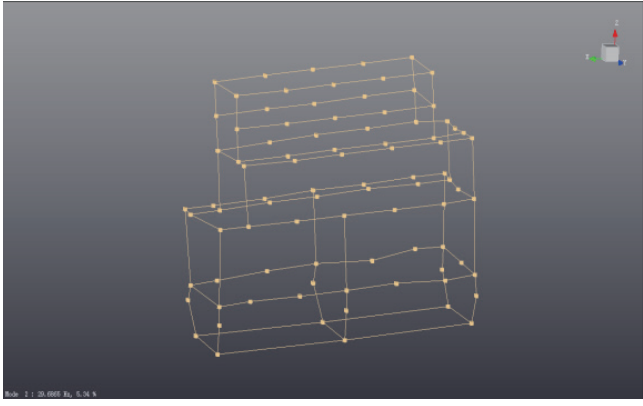

(a)

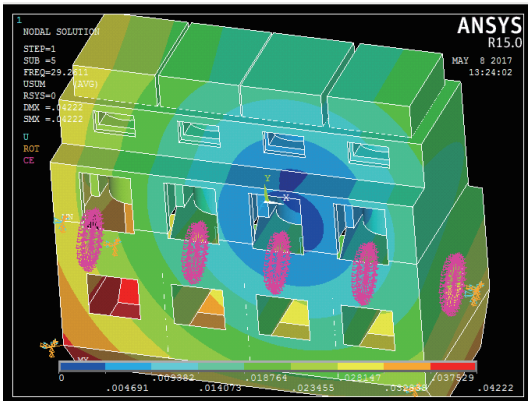

(b)

Fig. 16. (Color online) Vibration mode and frequency in the fifth-order system of the 4190 ZLC engine. (a) Natural frequency of $29.686 \mathrm{~Hz}$. (b) Simulation result of $29.261 \mathrm{~Hz}$.

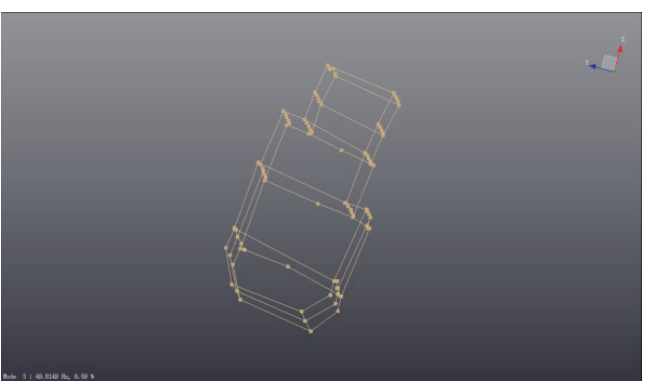

(a)

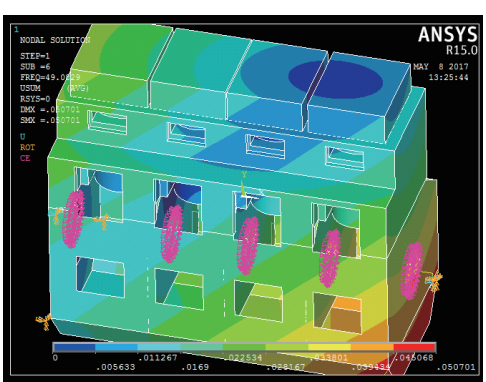

(b)

Fig. 17. (Color online) Vibration mode and frequency in the sixth-order system of the 4190 ZLC engine. (a) Natural frequency of $49.815 \mathrm{~Hz}$. (b) Simulation result of $49.083 \mathrm{~Hz}$. 
product concept to production and will enhance the design and help establish critical design parameters through improved accuracy and a simplified design cycle.

\section{Conclusions}

To understand the dynamics and characteristics of vibration of a marine diesel engine, a simulation model of a 4190 ZLC marine diesel engine was proposed for modal analysis. The model was validated by comparing the results with experimental data obtained from a tri-axial vibration sensor. It was important to collect accurate data from the sensor in this research. Thus, the measured data were processed by using an LMS system. The results provided the actual modal frequencies and corresponding vibration modes of the 4190 ZLC engine. A simulation model based on the FEM was established for calculating the frequencies. In the model, small but complex structures that had little effect on the overall vibration response were simplified. The frequencies of the simulation result were less than $1.5 \%$ different from those of the experimental data in the fourth-, fifth-, and sixth-order systems. The results of the simulation of the proposed model suggest that the modal analysis of the natural frequency and vibration mode with the FEM model was successfully applied to dynamic analysis. Therefore, the results of the modal analysis will provide a basis for how to optimize the design of marine diesel engines to reduce their vibration and for diagnosing the faults caused by vibration.

\section{Acknowledgments}

This study and some of the analysis were carried out with the assistance of Fujian Province Key Laboratory of Ship \& Ocean Engineering, Fujian Engineering Research Center of Marine Detecting and Remanufacturing. The authors gratefully acknowledge Fujian Science and Technology Projects (Nos. 2020H0018, 2019H0020, 2018J01494, and 2018J01498). This work was also supported by the National Fund Cultivation Program of Jimei University (2P2020008).

\section{References}

1 IMO Resolution A.468(XII): Code on Noise Levels on Board Ships (IMO A.468), International Marine Organization Eds. (1981). https://puc.overheid.nl/nsi/doc/PUC 2417 14/ (accessed March 2021).

2 J. H. Park and K. J. Kim: Inter. J. Prec. Eng. Manufact. 14 (2013) 1433. https://doi.org/10.1007/s12541-013-01939

3 M. M. A. Kadhim, A. H. Adheem, and A. R. Jawdhari: Inter. J. Civil. Eng. 17 (2019) 1295. https://doi. org/10.1007/s40999-018-0387-8

4 B. G. Liang, H. L. Yu, and Y. N. Cai: J. Vibroeng. 16 (2014) 3052. http://lib.cqvip.com/Qikan/Article/ Detail?id $=663016759$

5 Y. N. Cai, H. L. Yu, B. N. Liang, Y. C. Song, and J. Yan: J. Vibroeng. 18 (2016) 2088. https://doi.org/10.21595/ jve.2016.16862

6 B. N. Liang, H. L. Yu, and Y. N. Cai: J. Vibroeng. 18 (2016) 1991. https://doi.org/10.21595/jve.2016.16774

7 X. L. Li, Z. Q. Cui, T. X. Su, S. W. Yang, B. C. Zhang, and D. Q. Zhao: Chinese. Inter. Combust. Engine. Eng. 23 (2002) 16. https://doi.org/10.3969/j.issn.1000-0925.2002.01.005

8 J. Q. Tang, J. Q. E, Q. S. Zuo, and X. Wu: Sci. Tech. 45 (2014) 3015. http://www.cnki.com.cn/Article/ CJFDTotal-ZNGD201409012.htm

9 F. L. Fang, H. T. Yu, G. Q. Zhang, and K. Y. Zhang: Mach. Des. Manufact. 8 (2018) 192. https://doi. org/10.3969/j.issn.1001-3997.2018.08.055 
10 J. Wu, Z. C. Li, and T. He: Comp. Aid. Eng. 28 (2019) 37. http://www.cqvip.com/qikan/Detail. aspx?gch $=98105 X \&$ years $=2019 \&$ num $=04$

11 X. F. Du, G. Q. Shu, H. Q. Wei, and X. Y. Liang: J. Vibrat. Shock. 21 (2015) 157. https://doi.org/ JournalArticle/5b3c284bc095d70f00aafa9d

12 R. F. Yang and Z. Q. Cui: Chinese. Inter. Combust. Engine Eng. 24 (2003) 20. https://doi.org/10.3969/j. issn.1000-0925.2003.03.006

13 B. Liu, J. L. Liu, C. X. Lv, and H. C. Zang: Logist. Eng. Manag. 33 (2011) 109. https://doi.org/10.3969/j. issn.1674-4993.2011.09.049

14 X. L. Deng and H. L. Gao: Nat. Sci. 27 (2005) 426. https://doi.org/10.3969/j.issn.1672-948X.2005.05.012

15 J. Liang and D. F. Zhao: Modern. Manufact. Eng. 8 (2006) 139. https://doi.org/10.3969/j.issn.16713133.2006.08.049

16 R. J. Curry and G. S. Langdon: Intern. J. Impact. Eng. 102 (2017). https://doi.org/10.1016/j.ijimpeng.2016.12.004

17 P. D. Walker and N. Zhang: Mechan. Mach. Theory 77 (2014) 1. https://doi.org/10.1016/j. mechmachtheory.2014.02.008

18 M. Bodaghi and M. Shakeri: Compos. Struct. 5 (2012) 94. https://doi.org/10.1016/j.rinp.2018.10.019

19 J. Vanwalleghem, I. De Baere, M. Loccufier, and P. Wim: Sound. Vibrat. 6 (2014) 333. https://doi.org/10.1016/j. jsv.2013.10.015

\section{About the Authors}

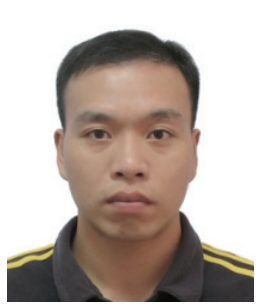

Jianbin Liao is a vice-professor of Jimei University and currently a Ph.D. candidate of Dalian Maritime University. He received his B.S. and M.S. degrees, both in marine engineering, from Jimei University in 1998 and 2007, respectively. His current research interests include marine engineering and fault diagnosis.

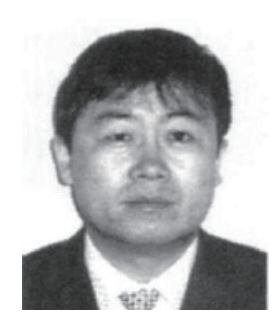

Hongliang Yu received his Ph.D. degree from Kobe University of Mercantile Marine, Japan, in 2002. He is now a professor in Jimei University, Xiamen, China. His major research interests include modern marine engineering management, vibration fault diagnosis, module shipbuilding, and reliability.

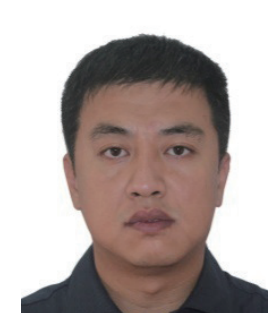

Jin Yan received his Ph.D. degree from Dalian Maritime University, Dalian, China, in 2013. His major research interests include vibration and noise testing, and analysis and control of the structure and equipment of ships.

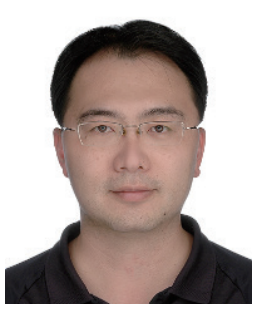

Shih-Hsien Hsu received his M.S. degree in electrical engineering from National Yunlin University of Science and Technology in 2005 and a Ph.D. degree in naval mechatronic engineering from National Cheng Kung University in 2015. Currently, he is an assistant professor in the Department of Electrical Engineering at Feng Chia University, Taiwan. His main research interests include power system analysis and energy savings in marine electrical systems. (shihhhsu@fcu.edu.tw) 